\title{
ADULT ONSET STILL'S DISEASE AS FEVER OF UNKNOWN ORIGIN - A CASE REPORT
}

Marco Antonio Gonçalves Pontes Filho ${ }^{1,2, *}$, Erickson Gomes Gutierrez², Gabriela Ferreira Rocha², Jéssica Tomps Corrêa², Lucas Guimarães Nolasco Farias ${ }^{2}$, Mateus de Medeiros Rijo ${ }^{3}$, Natália Fernandes Malfacini ${ }^{3}$ Patrícia Lúcia Silva Sampaio Leite ${ }^{3}$, Pedro Gustavo Barbosa Lira ${ }^{3}$, Victor Gomes Rocha ${ }^{4}$, Mariana Sandy Mada ${ }^{5}$, Vinícius Shinoda Pereira ${ }^{6}$

1. Universidade de São Paulo, São Paulo (SP), Brazil. 2. Hospital Ipiranga - UGA II, São Paulo (SP), Brazil. 3. Universidade Federal de Alagoas, Maceió (AL), Brazil. 4. Universidade Tiradentes, Maceió (AL), Brazil. 5. Universidade Federal de Santa Catarina, Florianópolis (SC), Brazil. 6. Centro Universitário de Maringá, Maringá (PR), Brazil.

*Corresponding author: marco.filho@hc.fm.usp.br

\section{BACKGROUND}

Fevers of unknown origin (FUOs) remain one of the most difficult diagnostic challenges in medicine. When long-lasting fever is associated with splenomegaly, numerous disorders are in the differential diagnosis, such as infectious, rheumatological and hematological. Among rheumatological, adult-onset Still's disease (AOSD) constitutes approximately 59\% of cases of FUOs, although it is a rare systemic condition. This is an inflammatory disease characterized by spiking fever, arthralgia/arthritis and skin rash, other findings including pharyngitis/sore throat, lymphadenopathy, hepatosplenomegaly and myalgia. The etiology is unknown and partially understood, and it is suggested that genetic factors and infectious triggers may be involved. Adult-onset Still's disease can evolve with macrophage activation syndrome (MAS), which is potentially fatal.

\section{CASE REPORT}

A 24-year-old white woman was admitted to the ward with a history of fever and malaise for 4 weeks. She also complained of polyarthralgia on hands, wrists, feet and low back pain. Physical examination showed paleness, presence of two palpable and painful lymph nodes (measuring $1 \mathrm{~cm}$ ) in bilateral cervical chains. On palpation of the abdomen, there was pain on left and right hypochondrium, dullness on Traube's space and the presence of painful hepatosplenomegaly. Laboratory tests showed moderate pancytopenia, CRP $3.1 \mathrm{mg} / \mathrm{dL}$ and ESR $65 \mathrm{~mm}$, elevated transaminases (AST 143U/L; ALT 62U/L; GGT 341U/L) and elevated serum ferritin 3,140 ng/mL. In abdominal images, hepatosplenomegaly was found, with spleen measuring $23.5 \times 16.5 \times 10.5 \mathrm{~cm}$, with no other changes. A myelogram was performed and revealed hypercellular bone marrow with dysgranulopoiesis, dyserythropoiesis and megakaryocytic hyperplasia, but no signs of MAS. Serologies for hepatitis B and C, HIV, syphilis, Arbovirus and mononucleosislike syndromes (Epstein-Baar, Cytomegalovirus, Parvovirus B19, toxoplasmosis) were negative. Antinuclear antibody (ANA) and rheumatoid factor were also negative. Thyroid function tests were normal. During hospitalization, the patient presented fever, and after exclusion of secondary infections with negative cultures, she was diagnosed with AOSD (Table 1). She received prednisone $1 \mathrm{mg} / \mathrm{kg} /$ day, with improvement of signs, symptoms and normalization of laboratory tests.

\section{CONCLUSION}

Characteristic history and physical examination findings together with key nonspecific test abnormalities are the basis for a focused clue-directed FUO work-up. In cases of FUO associated with hepatosplenomegaly, AOSD should be considered among differential diagnosis, especially if associated with hyperferritinemia. Although it may present serious complications such as MAS, its prognosis is good, and mortality is low. A high index of suspicion at presentation to avoid unnecessary diagnostic procedures must be necessary, in order to make a prompt diagnosis, and institute the most effective management for this condition. 
Table 1. Adult-onset Still's disease (AOSD) diagnostic criteria.

\begin{tabular}{|c|c|c|}
\hline Yamaguchi et al. & Fautrel et al. & Cush \\
\hline Major (2 points each) & Spiking fever $\geq 39^{\circ} \mathrm{C}$ & Quotidian fever $\geq 39^{\circ} \mathrm{C}$ \\
\hline $\begin{array}{c}\text { Arthralgia }>2 \text { weeks } \\
\text { Fever }>39^{\circ} \mathrm{C}, \text { intermittent } \geq 1 \text { week } \\
\text { Typical rash } \\
\text { WBC }>10,000 \\
\text { (>80\% granulocytes })\end{array}$ & $\begin{array}{c}\text { Arthralgia } \\
\text { Transient Erythema } \\
\text { Pharyngitis } \\
\text { PMN } \geq 80 \% \\
\text { Glycosylated ferritin } \leq 20 \%\end{array}$ & $\begin{array}{c}\text { Still evanescent rash } \\
\begin{array}{c}\text { WBC }>12.0+E S R>40 \mathrm{~mm} / 1 \mathrm{st} h \\
\text { Negative } \mathrm{RF} \text { and ANA } \\
\text { Carpal ankylosis }\end{array}\end{array}$ \\
\hline $\begin{array}{c}\text { Minor (1 point each) } \\
\text { Sore throat } \\
\text { Lymphadenopathy and/or splenomegaly } \\
\text { LFT abnormal } \\
\text { Negative ANA and RF }\end{array}$ & $\begin{array}{c}\text { Maculopapular rash } \\
\text { Leukocytes } \geq 10 \times 109 / \mathrm{L}\end{array}$ & $\begin{array}{c}\text { Onset age }<35 \text { years } \\
\text { Arthritis } \\
\text { RES involvement or abnormal LFTs } \\
\text { Serositis } \\
\text { Cervical or tarsal ankylosis }\end{array}$ \\
\hline \multicolumn{3}{|c|}{ Diagnosis } \\
\hline Five criteria (at least two major) & Four major & najor + two minor \\
\hline
\end{tabular}

WBC: White blood cell, PMN: Polymorphonuclear leucocyte; ESR: Erythrocyte sedimentation rate; RF: Rheumatoid factor; ANA: Antinuclear antibody 